\title{
El valor probatorio de la información exógena tributaria en Colombia
}

\section{The evidentiary value of Exogenous Tax Information in Colombia}

\author{
JUAN ANDRÉS GONZÁLEZ MONTES ${ }^{1}$
}

\section{Resumen}

La prueba es la herramienta que le permite al juez de la administración de impuestos el esclarecimiento de los hechos materia de controversia, llegando a una convicción respecto de la realidad misma que le permite fallar en justicia, lo cual es el resultado de un análisis crítico, profundo, juicioso y libre de vicios, lo que le permite creer que la solución del conflicto coincide con la verdad de los hechos.

Así, la información exógena es un elemento probatorio y, como tal, está sujeto al principio de publicidad y contradicción ${ }^{2}$.

Dependiendo de la forma como se desarrollan los hechos del proceso de discusión tributaria, dicha prueba, en ciertos casos, puede ser insumo directo del fallo por parte de la jurisdicción en contra del contribuyente, pues el levantamiento de la presunción de veracidad de las declaraciones tributarias, en armonía con la aplicación del juicio de valoración de las pruebas aportadas por el contribuyente, convierte la información exógena en prueba contundente de inexactitud tributaria. Además, cuando la relación entre el hecho indicador y el hecho indicado es tan estrecha, permite tener certeza de la vulneración de ley, generada por el incumplimiento de obligaciones sustantivas o deberes formales.

Palabras clave: Hecho objeto de prueba, Indicio, Información exógena, Prueba directa, Prueba indirecta, Derecho al debido proceso, Derecho de contradicción, Principio de publicidad.

\begin{abstract}
The test is the tool that allows the judge of the tax administration to clarify the facts matter of controversy, coming to a convic-
\end{abstract}

${ }^{1}$ Contador Universidad Libre Seccional Pereira, especialista en Derecho Administrativo de la misma universidad, especialista en Legislación Tributaria y Aduanera Universidad de Caldas. Maestría en Derecho del Estado con énfasis en Tributación de la Universidad Externado de Colombia. Correo-e: anjudres@hotmail.com DOI: https://doi.org/10.18601/16926722.n13.09

${ }^{2}$ Decreto 624, marzo 30 de 1989, Artículo 750. 
tion on the reality itself that allows him to fail in justice, that conviction ces the result of a Critical analysis, deep, judicious and free of vices, which allows him to believe that the resolution of the solution of the conflict coincides with the truth of the facts.

The principle of legality is not alien to the evidentiary issue and its rules applicable to the different means of proof allow the judge not to accept the test alone, on the contrary, appreciate it, value it according to its conviction, its rationing and legal knowledge.

Exogenous information constitutes testimonial evidence and as such is subject to the principle of publicity and contradiction. Being subject to these principles is where it ceases to be direct proof, to become an indication, in indirect proof of the existence of an economic fact source of tax obligation. Allowing the managed or the administration what suits them.

Depending on how the facts of the tax discussion process are developed, such testimonial evidence in certain cases may be a direct input of failure against the taxpayer; Since the lifting of the presumption of veracity of the tax declarations in harmony with the application of the judgement of valuation of the tests contributed by the taxpayer converts to the exogenous information in conclusive proof of tax inaccuracy. Moreover, when the relation between the indicator fact and the indicated fact is so narrow, it allows to be certain of the infringement of law, generated by the breach of substantive obligations or formal duties,

Keywords: Test object fact, Clue, Exogenous information, Direct proof, Indirect proof, Due process right, Contradiction right, Advertising principle.

\section{Introducción}

En el proceso de discusión tributaria que se entabla entre la administración y el contribuyente, se busca revelar una realidad económica que dé lugar al pago de exacciones y al cumplimiento de una serie de deberes formales, lo cual se enmarca en un tema probatorio que es fundamental para tratar de dilucidar la verdad.

Dicha verdad, que es la fuente generadora de la debida contribución bajo el mandato constitucional de justicia y equidad, se cimienta en que las partes puedan probarse mutuamente sus afirmaciones y, para ello, corresponde a cada uno tratar de demostrarlas mediante los mecanismos y elementos que otorga la ley. En este contexto, el presente trabajo aborda el tema probatorio en materia tributaria, específicamente en lo referente a la información exógena y su aporte probatorio, analizada desde una perspectiva indirecta como indicio.

\section{Aspectos dogmáticos de la prueba}

\section{A. Características, importancia y clases}

"Etimológicamente, prueba proviene del latín probus que significa bueno, honrado, que te puedes fiar de él" (Anders, s. f.).

Según Carnelutti y Rocco, la expresión prueba "tiene un distinto significado en el lenguaje común y jurídico, pues prueba judicial es la comprobación, no de los hechos, sino de las afirmaciones (Carnelutti, s. f.,p. 674). 
A ello podríamos agregar que en materia procesal se puede hablar de prueba solo cuando se trate de comprobar hechos que están sujetos a contradicción y que no han sido admitidos por ambas partes dentro del proceso judicial.

En síntesis, la obligación de probar dependerá de la situación adquirida por las partes en un proceso. Cada una de ellas deberá probar los hechos sobre los que funda su defensa. La prueba se podría definir como la actividad de las partes dentro de un proceso judicial o procedimiento administrativo, dirigida a convencer al juez o al administrador de la veracidad de unos determinados hechos que se afirman existentes en la realidad ${ }^{3}$.

Nuestro código general del proceso, Ley 1564 de diciembre 12 de 2012, en su Artículo 168 , establece que los jueces rechazarán, mediante providencia motivada, las pruebas ilícitas, las notoriamente impertinentes, las inconducentes y las manifiestamente superfluas o inútiles. Ello lleva a encontrar que la actividad probatoria se rige por unos principios, los cuales están definidos así:

1) Principio de libertad de prueba: para alcanzar la verdad concreta no se requiere la utilización de un medio de prueba determinado. Todos los medios de prueba son admisibles, es decir, se puede probar con los medios típicos como también con aquellos que no han sido contemplados en la ley (atípicos), siempre y cuando no recaigan en la ilicitud.
2) Principio de pertinencia: en virtud del cual debe existir relación entre el hecho o circunstancia que se quiere acreditar con el elemento de prueba que se pretende utilizar.

3) Principio de conducencia y utilidad: se refiere este principio a la relevancia que tienen los hechos probados, si estos van a ser útiles para resolver el caso en particular. Una razón de inutilidad de la prueba es la superabundancia, es decir, cantidad excesiva de elementos de prueba referidos al mismo hecho.

4) Principio de legitimidad: tiene que ver con alguna prohibición o impedimento que expresamente declare el ordenamiento jurídico, procesal, respecto a un medio de prueba. Están prohibidos aquellos medios de prueba que van contra la dignidad o integridad de las personas, o que se hubieren obtenido por medios ilícitos o que violenten de alguna manera los derechos de alguna de las partes.

En este orden de ideas, podríamos decir que el objetivo de la prueba es esclarecer un hecho que no es suficientemente claro, que genera duda, que su existencia, o no, conlleva un derecho o una obligación para las partes involucradas en el proceso de discusión, que para nuestro caso será el proceso de discusión tributaria.

Adicionalmente, no se puede pasar por alto que la valorización objetiva de la prueba está directamente ligada al debido proceso, al derecho de defensa, como elemento para

${ }^{3}$ Actualidad Jurídica 2012, Editorial Azuaje. 
poder generar justicia. Es decir que, dentro del procedimiento, que para nuestro caso es administrativo, el juez debe velar porque se cumplan las garantías mínimas al contribuyente investigado.

En este sentido, Santofimio Gamboa expresa que "el más amplio sistema de garantías que procura, a través de la realización del derecho material, la obtención de decisiones justas, y en esa medida dentro de la variedad de elementos que lo materializan, se hallan los de ofrecer y producir pruebas y obtener decisiones fundadas o motivadas con arreglo a las pruebas legalmente obtenidas y valoradas conforme a las reglas de la lógica y la sana crítica" (Santofimio Gamboa, 2006). Es así como vemos una vez más la importancia de la prueba ahora ligada al debido proceso, la cual permite, como ya se ha dicho, después de una valoración objetiva, generar justicia en su deber ser.

Ahora bien, una vez visto qué es la prueba, sus principios, características y su objetivo en el proceso jurídico, es necesario clasificarlas a fin de ir dejando de lado lo que no es centro de estudio de este trabajo, de tal manera que podamos embarcarnos a donde queremos llegar: la información exógena como prueba indiciaria en el proceso de discusión tributaria.

Adicionalmente, es importante recordar que "la prueba Directa o también llamada prueba inmediata, es la que tiene por objeto la obtención de asertos que, al ser comparados con los contenidos en las alegaciones, permitirán comprobar la veracidad de las mismas. Son pruebas directas, en este sentido, las reguladas en las normas adjetivas. Se habla de prueba directa para referirse a la que es percibida de manera personal y directa por el juzgador, como la inspección ocular ${ }^{4}$.

La prueba indirecta es todo lo contrario a la prueba directa, está constituida por indicios, por inducciones, por consecuencias derivadas de un hecho conocido, que llevan a establecer un hecho pendiente de prueba.

En este punto ya nos encontramos ubicados en la prueba indiciaria, que como su nombre lo indica, son indicios, conjeturas, indicaciones, señales, presunciones, que al tener un proceso de experiencia, ciencia o lógica se vuelven decisivos y, en ultimas, son aceptados por un juez como conclusión lógica de la existencia de un hecho.

\section{La prueba en materia tributaria}

El régimen probatorio en materia tributaria en Colombia fue consagrado inicialmente en el Decreto 1651 de 1961, aplicable únicamente al impuesto de renta y complementarios, y estaba dividido en dos capítulos. El primero, normas generales, en el cual se hacían precisiones acerca de los criterios para la valoración de las pruebas y la definición de la carga de la prueba respecto del contribuyente. El segundo, medios de prueba específicos, en el cual se definían las características de cada uno de los medios de prueba.

\footnotetext{
${ }^{4}$ Prueba directa, disponible en: Enciclopedia-juridica.biz14.com, URL: http://www.enciclopediajuridica.biz14.com/d/prueba-directa/prueba-directa.htm.
} 
Posteriormente, se introducen modificaciones referentes a la materia, así: Ley 52 de 1977, Decreto Extraordinario 2821 de 1974, Decretos-Ley 2053 de 1974 y 3803 de 1982.

Por último, el hoy vigente Decreto $684 \mathrm{de}$ 1989, mediante el cual se expide el Estatuto Tributario, compila las normas vigentes en materia de pruebas, y en el título VI, "Régimen probatorio", se organizan en tres capítulos (Arts. 742 al 791). El primero contiene disposiciones generales; el segundo, los medios de prueba específicos, y el tercero, las circunstancias especiales que deben ser aprobadas por el contribuyente.

La primera disposición, esto es, el Artículo 742 , establece que las decisiones de la administración de impuestos deben fundamentarse en hechos probados, y para ello permite aplicar el régimen probatorio del Código de Procedimiento Civil, hoy Código General del Proceso.

Ahora, dado que las pruebas son determinantes en el debido proceso, tal como lo consagra el Artículo 29 de la Constitución Política de Colombia, se debe tener presente que la actividad probatoria en materia tributaria conlleva dos escenarios concurrentes entre sí.

El primero es la identificación clara de los hechos que son o deben ser materia de comprobación, y el segundo hace referencia a la carga de la prueba, es decir, determinar cuándo esta corresponde a la administración o al administrado, la cual en principio está en cabeza del contribuyente.

Pese a lo anterior, existen autores como Hensel, que en su obra Derecho tributario afirma que "la autoridad tributaria debe probar todas las circunstancias de hecho y de derecho determinantes de la obligación tributaria, el obligado tributario tiene que demostrar los presupuestos de una deducción, exención, devolución"

Esto, al final, no es otra cosa que las partes deben probar sus beneficios. La administración debe dar cuenta de la existencia de activos e ingresos del contribuyente, y el administrado debe demostrar la existencia de pasivos, rentas exentas, ingresos no constitutivos de renta, costos, deducciones, retenciones en la fuente y descuentos tributarios.

Ejemplo de ello es lo establecido en los Artículos 786 a 791, donde la carga de la prueba esta únicamente en cabeza del contribuyente para demostrar que recibió ingresos no constitutivos de renta, demostrar la existencia de un gasto con el lleno de requisitos legales cuando el tercero niega el pago, demostrar el derecho a exenciones, demostrar las razones que justifican los incrementos patrimoniales y demostrar las operaciones realizadas con personas fallecidas.

Así, nos avocamos a un proceso que parte de una norma sustantiva que consagra todos aquellos elementos que permiten determinar la carga de la prueba.

${ }^{5}$ Cfr. Hensel (s. f., p. 335). 
En cuanto a la calificación y valoración de los medios de prueba, se deben tener presentes dos criterios básicos, los cuales encontramos en los Artículos 743 y 770 del Estatuto Tributario, referente a la idoneidad y a la conducencia; así:

Artículo 743 del estatuto tributario, Idoneidad de los medios de prueba: La idoneidad de los medios de prueba depende, en primer término, de las exigencias que para establecer determinados hechos preceptúen las leyes tributarias o las leyes que regulan el hecho por demostrarse y a falta de unas y otras, de su mayor o menor conexión con el hecho que trata de probarse y del valor de convencimiento que pueda atribuírseles de acuerdo con las reglas de la sana crítica.

La segunda disposición se refiere a la conducencia de la prueba, es decir, que obliga al contribuyente y a la administración a verificar si frente al hecho que debe probarse, la ley tributaria o la normatividad que rige otras disciplinas específicas, como la comercial o la civil, exigen una prueba determinada para probar tal hecho, como sería el caso de los pasivos que tratándose de contribuyentes no obligados a llevar libros de contabilidad deben estar soportados en documentos de fecha cierta, lo cual indica que una prueba distinta a los documentos de fecha cierta resulta inconducente (Art. 770 E.T.).

Sin embargo, la conducencia de la prueba en el régimen probatorio tributario está normalmente determinada, no porque la ley exija una prueba específica, sino por el incumplimiento de requisitos formales. Ejemplo de ello son los requisitos que debe cumplir la factura de venta para que el hecho allí generado sea reconocido como costo o gasto fiscal, es decir, independientemente de que estos sean reales o existan otros medios de prueba para soportarlos, no podrá accederse a su reconocimiento por estar así determinado expresamente en la ley.

Algunos principios básicos rigen la actividad probatoria, como son la necesidad de la prueba, la idoneidad de esta, la oportunidad para allegarla al expediente, el principio in dubio pro contribuyente que consagra el Artículo 745 del Estatuto Tributario, en virtud del cual las dudas provenientes de vacíos probatorios al momento de practicar las liquidaciones o de fallar los recursos deben ser resueltas a favor del contribuyente, esto es, sin perjuicio de la posibilidad que tiene la administración de eliminarla o el operador judicial de decretar pruebas de oficio, así como de la presunción de veracidad de los hechos consignados en las declaraciones tributarias que consagra el Artículo 746 del mismo ordenamiento.

Sobre los medios de prueba específicos, el régimen probatorio tributario consagra como tales los siguientes: la confesión -simple o presunta-, los testimonios, la prueba documental, la contabilidad, ya sea que se allegue a través de la inspección contable certificado de contador público o revisor fiscal, la inspección tributaria, los indicios, las presunciones y el dictamen pericial.

El Estatuto Tributario enuncia las características generales de cada uno de los medios de prueba y delimitan su aplicación, como es el caso de los indicios que consagra el Artículo 754.

Adicionalmente, en algunos casos concretos se establece la inadmisibilidad, como es 
el caso de la prueba testimonial, cuando se advierte que no es aceptable para demostrar hechos que por su naturaleza suponen la existencia de documentos escritos (Art. 752 E.T.). En todo caso, en lo no regulado para estos medios de prueba, son aplicables las normas generales del Código General del Proceso.

\section{A. Indicio como prueba en materia de impuestos}

Para hacer referencia a la definición de indicio como medio de prueba, tomaremos como referencia lo manifestado por los profesores Gustavo Humberto Rodríguez, Sergio García Ramírez, C. J. A. Mittermaier, Antonio Dellepiane, Jorge Arenas Salazar y Yesid Reyes Alvarado, así:

El profesor Rodríguez clasifica el indicio en tres grupos: el indicio es el hecho indiciario, el indicio es la inferencia lógica y el indicio es todo el proceso (Rodríguez, s. f., pp. 308 y 309).

En cuanto al primer aspecto, "es la acepción corriente según la cual se denomina indicio el hecho indicante e indicador o indiciario, a la circunstancia que es causa o efecto de delito: la huella digital, la mancha de sangre, la fuga, etc.".

Respecto al segundo: "el indicio no es el hecho indicador, sino el racionamiento, la operación mental de inferencia lógica que hace el juzgador, la relación de causalidad entre el hecho indicador conocido y demostrador y el hecho desconocido que va a probar el delito".
"El indicio es todo el proceso: de acuerdo con esta acepción, comprende tres elementos: el hecho indicador, el hecho indicado o desconocido y la inferencia lógica o relación de causalidad entre ellos".

Por otra parte, García Ramírez (1974, p. 326), referente a la definición de indicio, ha dicho: "Los indicios son hechos, datos o circunstancias ciertos y conocidos de lo que se desprende, mediante elaboración lógica, la existencia de otras circunstancias, hechos o datos desconocidos".

Mittermaier, en su obra Tratado de la prueba en materia criminal (Mittermaier, s. f., p. 439) ha definido indicio como: "Un hecho que está en relación tan íntima con otro hecho, que el juez llega del uno al otro por medio de una conclusión muy natural. Por eso son menester en la causa: el uno comprobando, el otro no manifiesto aún y que se trata de demostrar raciocinando del hecho conocido al desconocido".

Por otra parte, Dellepiane (1983, p 57) ha dicho sobre el tema: "Indicio es todo rastro, vestigio, huella, circunstancia y, en general, todo hecho conocido o mejor dicho debidamente comprobado, susceptible de llevarnos, por vía de inferencia, al conocimiento de otro hecho desconocido".

Arenas Salazar (1988, p. 22) ha dicho: "Consideramos por nuestra parte, que el indicio es el medio de prueba resultante de una operación lógica mediante la cual, a partir de una circunstancia fáctica plenamente demostrada en el proceso, se infiere la existencia de otro hecho llamado indicado. ... El indicio no puede ser un medio de prueba resultante de una operación lógica, sino precisamente, 
un hecho que nos permite traer al proceso otro hecho".

Por último, Reyes Alvarado (1984, p. 13) ha dicho: el indicio "es un juicio lógico por medio del cual, aplicando una regla de experiencia a un hecho conocido, podemos inferir otro hasta entonces desconocido".

En términos generales, los autores toman parte de una realidad conocida para inferir una consecuencia.

En este orden de ideas, se pueden enlazar circunstancias como la omisión o inexactitud tributaria, basados en fuentes de información externa recibidos por la administración de impuestos como prueba indirecta (hechos conocidos), que nos pueden llevar a un indicio de evasión fiscal.

Ahora bien, existe poca literatura que hable sobre los indicios en materia tributaria, pues la ley dice que las decisiones de la administración deben basarse en hechos probados.

De tal manera que para algunos no reviste importancia hablar de indicios en tributación, pero habrá a quienes sí les llame la atención conocer toda la cadena y las consecuencias de un indicio en esta materia, dado que la gran mayoría de los expedientes por posibles omisiones de ingresos nacen de los cruces de información que generan indicios de inexactitud, y es ahí donde reviste gran importancia la información exógena como indicio, pues gracias a ella, se conocen las transacciones y hechos económicos de los contribuyentes, se generan más controles, se adelantan más programas de fiscalización, se aumenta el recaudo, se disminuye la evasión.
Dentro de los programas de fiscalización que adelanta la administración de impuestos tomando como base la información exógena, encontramos: omisos declarantes, inexactos, declaraciones sombra, etc., convirtiéndose dicho insumo de información en prueba indiciaria en la determinación de obligaciones formales, en prueba indiciaria de inexactitudes cuando la información de un mismo tercero difiere su valor entre la contabilidad del investigado vs. el reporte en medios magnéticos del informado.

Ahora, para entrar un poco más en materia, pretendo abordar puntualmente unos temas mencionados a continuación, que servirán de base para ver cómo el indicio es la pieza fundamental, es el elemento esencial de un adecuado control tributario:

\section{La información exógena como resumen} de hechos económicos, que constituyen prueba indiciaria de la existencia del hecho generador de la obligación

\section{tributaria}

Nace de la esencia misma de la economía que todas las transacciones incurridas por las diferentes personas que convergen en ella, bien sea como productoras, comercializadoras o simplemente consumidoras, son hechos económicos, hechos que se resumen en la contabilidad y toman como base formal un documento al que la misma ley le ha dado dicha categoría como soporte contable, lo cual no quiere decir que el soporte reemplaza la existencia de un hecho económico; por el contrario, es el complemento que materializa su existencia y es prueba ante diferentes entidades de control o ante conflictos que resultan por la dinámica misma del ejercicio particular de las personas. 
Estos hechos económicos, acompañados de los documentos que acreditan su existencia y la contabilidad como resumen, son toda la información que soporta el reporte en medios magnéticos. Es decir, lo que se reporta a la administración de impuestos no es otra cosa que la existencia de transacciones económicas entre dos personas involucradas que hacen parte de la economía, hacen parte del negocio jurídico, y que su conocimiento por parte de las entidades de control tributario sirve como fuente para verificación del cumplimiento adecuado de las obligaciones tributarias.

De tal manera que conocer de la existencia de un hecho económico, una transacción económica, un negocio jurídico, realizado por un contribuyente que ha omitido sus obligaciones con el Estado de contribuir por la realización del mismo genera indicio de posibles evasiones tributarias, indicios que unidos a otras circunstancias de medio, tales como requerimientos ordinarios, inspecciones contables y una adecuada conexión entre las mismas lleva a la demostración de la existencia del hecho generador de la obligación tributaria, revistiendo suma importancia para la información exógena como pilar inicial de la investigación, como fundamento de apertura, como indicio de inexactitud, como prueba indirecta.

\section{a. Necesidad de los cruces de información como prueba indiciaria}

La prueba indiciaria es aquella que como su nombre lo indica produce indicio de la existencia de un hecho, que por sí solo no reviste mayor relevancia, pero al volverla dinámica con el proceso, al armonizarla con la historia del mismo, al aplicarle las reglas de la experiencia y la ciencia, pueden conducir a otros hechos que, en últimas, concluyen en la responsabilidad omisiva del contribuyente.

A manera de ejemplo: un residente colombiano incurre en gastos por USD30.000.oo en Europa durante 60 días, cancelados con su tarjeta de crédito de un banco colombiano. Dicho hecho, por sí solo, no genera ninguna importancia para la administración tributaria nacional, pues estas erogaciones fueron ingresos para contribuyentes de otro país en el cual Colombia no tiene jurisdicción de fiscalización.

Pero resulta que observando la historia del proceso que se adelanta, hace referencia a una diferencia patrimonial. Logramos así hacer dinámico el hecho, pues los USD 30.000 son gastos no deducibles que inciden directamente en la conciliación patrimonial del contribuyente, mostrándonos así un segundo hecho, el cual puede ser una renta por comparación de patrimonios. Cabe mencionar que una vez establecido el indicio de posible omisión o inexactitud, la administración de impuestos cuenta con la facultad para confirmar dichas inconsistencias, desarrollar aún más los cruces de información por vías como requerimientos ordinarios, autos de verificación o cruce, inspecciones contables, etc., lo que permite confirmar o por el contrario desvirtuar la información encontrada en medios magnéticos.

\section{b. Relevancia de los indicios como método deductivo de la existencia del hecho generador}

La Corte Suprema de Justicia colombiana, Sala Penal, hace referencia al método deductivo como: "Aquel método cognoscitivo de proyecciones sustanciales que se iden- 
tifica en el plano general con la estructura del silogismo deductivo en el cual es dable identificar: i) la premisa menor o hecho indicador, ii) la premisa mayor o inferencia lógica en la que tienen operancia los ejercicios de verificabilidad de la sana crítica que se apoyan en leyes de la lógica, la ciencia y postulados de la reflexión y el raciocinio, y iii) las conclusiones o hecho indicado" 6 .

A pesar de que esta definición, al igual que todas las encontradas sobre el tema, hace referencia al silogismo deductivo desde el punto de vista penal, no es ilógico pensar que la definición dada pudiese aplicarse al Derecho tributario. Así, al conocer un dato gracias a la información exógena, como hecho indicador $\mathrm{y} / \mathrm{o}$ premisa menor de una posible evasión tributaria, que al ser sometido a la lógica, la ciencia, la experiencia, la reflexión y el raciocinio, logre indicar la existencia del hecho generador de la obligación impositiva.

Ejemplo: un incremento patrimonial aparentemente injustificado de un contribuyente $\mathrm{X}$ es el hecho indicador de una posible omisión de ingresos (premisa menor), al aplicarle la experiencia del funcionario, su lógica, su sagacidad, su conocimiento, y al apoyarse en la información exógena detecta que el contribuyente no posee bienes inmuebles que le pudiesen generar valorizaciones y de esa manera justificar la diferencia patrimo$\operatorname{nial}^{7}$ (premisa mayor), lo lleva a concluir que efectivamente el contribuyente $\mathrm{X}$, durante el año en investigación, cambió su vehículo adquiriéndolo de contado producto de ingresos que obtuvo y no declaró, generando así un hallazgo de omisión de ingresos (hecho indicado).

\section{c. El indicio grave como fuente de evasión tributaria}

Con respecto a la definición de indicio grave, tenemos:

\begin{abstract}
"El indicio es grave cuando la relación entre el hecho indicador y el indicado es tan estrecha que puede originar certeza" (Arenas, 1985, p. 176).
\end{abstract}

Una vez más, todas las definiciones son tomadas de literatura de orden penal; sin embargo, son plenamente aplicables al ámbito tributario, pues, como vimos anteriormente, los elementos del indicio los encontramos absolutamente en el campo que nos incumbe. Un ejemplo grave de indicio en materia tributaria sería: el contribuyente $\mathrm{X}$ no presentó declaración de renta por el año gravable 2016, puesto que consideró que no cumplía con los requisitos para estar obligado a ello ${ }^{8}$. Según información exógena reportada por el banco ZZ, durante el mismo año realizó consignaciones bancarias por valor de ciento cincuenta millones de pesos (\$150.000.000.oo). Con dicha información, sin necesidad de ahondar más en la investigación, el funcionario de la administración de impuestos puede proyectar un emplazamiento para declarar, pues la relación entre el hecho indicador

\footnotetext{
${ }^{6}$ Sentencia del 2 de septiembre de 2009, radicado 29.221, M.P. Yesid Ramírez Bastidas.

${ }^{7}$ Artículo 237, Decreto 624, marzo 30 de 1989.

${ }^{8}$ Artículos 592, 593,594-3, Decreto 624, marzo 30 de 1989.
} 
(consignaciones bancarias), gracias a la información exógena, es tan estrecha que conduce directamente al hecho indicado (obligación de declarar impuesto a la renta y complementario).

\section{Posición de la DIAN vs. posición del Consejo de Estado frente al valor probatorio de la información exógena}

La administración de impuestos ha pretendido en múltiples ocasiones provocar la corrección de las liquidaciones privadas de los contribuyentes con las sanciones correspondientes, tomando como base la información exógena suministrada por terceras personas.

Las discusiones tributarias han sido a tal punto que han agotado sede administrativa y han pasado en segunda instancia al Consejo de Estado, donde las decisiones de las salas convergen en que la información en medios magnéticos es simplemente un mecanismo de fiscalización y que las decisiones de los actos administrativos deben basarse en hechos probados, amparados en el contenido del Artículo 742 del Estatuto Tributario.

No obstante ello, considero que no existe una verdad revelada, que no existe una sola posición, que la posición tanto de la administración como del juez contencioso administrativo varía dependiendo del desarrollo de los hechos, de los argumentos, de las demás pruebas allegadas al proceso. En fin; de cualquier forma, es interesante conocer la postura que han manejado estas dos entidades a través del tiempo.
Cuando la DIAN, sin afirmar la existencia del valor probatorio, basa todo su fundamento sancionatorio en los cruces de información; cuando el Consejo de Estado dice rotundamente que no existe valor probatorio en la información exógena, o cuando en un par de sentencias la Sala induce a la irrelevancia de la misma, restándole importancia y necesidad, y aun así manifiesta que sirven como indicio, nos acercamos de cierta forma un poco más a lo que hemos planteado.

Ejemplo de la situación en mención es el caso de una contribuyente que presentó declaración de renta por el año gravable 2006. La administración de impuestos profirió requerimiento ordinario y especial y a ninguno de los dos la actora dio respuesta. La DIAN emitió liquidación oficial de revisión desconociendo pasivos, costos, deducciones y retenciones en la fuente, y aplicó sanción por no enviar información.

La actora manifestó dentro de sus argumentos de defensa para pretender el reconocimiento de sus pasivos, costos, deducciones y retenciones en la fuente que la DIAN ignoró la información exógena, y solicitó darle valor probatorio a la misma, pues todas las cifras desconocidas por la administración estaban previamente reportadas por terceras personas en medios magnéticos.

Esta sentencia ${ }^{9}$ es interesante porque no es la DIAN la que pretende indirectamente darle valor probatorio a los medios magnéticos; por el contrario, es un argumento de la contribuyente a su favor.Lamentablemente,

\footnotetext{
${ }^{9}$ Sentencia 20823, Radicación número 25000-23-27-000-2011-00249-01(20823), del 18 de febrero de 2016 .
} 
para juicio de este trabajo, ni la administración de impuestos ni la sala manifestaron pronunciamiento al respecto; se limitaron a valorar el resto de fundamentos de hecho y de derecho establecidos en sede administrativa, sin dedicarle un par de párrafos a lo que rogó la actora, restándole importancia a su súplica. De lo cual podemos concluir que no le dio valor probatorio ni siquiera como prueba indirecta o como indicio de la existencia de los costos, deducciones y pasivos.

El cruce de información no es en sí mismo una prueba sino un procedimiento que utiliza la Administración para verificar la exactitud de las declaraciones tributarias y del cual pueden surgir verdaderas pruebas cuya validez depende de las previsiones jurídicas aplicables y son estas las que debe considerar el funcionario (.) Los datos consignados en las declaraciones de terceros o en respuestas de estos a requerimientos administrativos relacionados con obligaciones tributarias del contribuyente, se tendrán como testimonio, sujeto a los principios de publicidad y contradicción de la prueba, se deduce de lo dispuesto en el Artículo 80 del Decreto 1651 de 1961 en concordancia con el inciso primero del Artículo 36 de la Ley 52 de 1977 que se mencionó antes ${ }^{10}$.

En esta misma línea, encontramos otra sentencia ${ }^{11}$ que ratifica lo planteado en el desarrollo de este trabajo. Por un lado, los errores de interpretación de la información exógena, lo cual ocasiona la dualidad de reporte del mismo hecho económico en varios formatos o por distintos contribuyentes, lo que genera confusión al funcionario público y acarrea un desgaste administrativo innecesario. Y, por otro lado, la Sala, sin concluir que la información exógena es prueba, sí le da la connotación de indicio.

El caso en concreto se refiere a un individuo que presentó declaración de renta por el año gravable 2007. La administración de impuestos profirió requerimiento especial, en el cual propuso adicionar ingresos, desconocer los ingresos no constitutivos de renta y de ganancia ocasional, desconocer retenciones en la fuente y aplicar sanción por inexactitud. Dicho requerimiento especial no fue respondido por parte de la actora, y fue confirmado por la DIAN mediante liquidación oficial de revisión.

La actora, como argumento de defensa, indicó que la Administración de impuestos debió de haber confirmado la información en medios magnéticos mediante requerimiento ordinario al informante, y solicitó se librara oficio para ello, a lo que la DIAN manifestó: "No es procedente solicitar a los terceros nuevamente la información, por cuanto las pruebas se encuentran incorporadas en el proceso y no tiene sentido reiterarla; es suficiente la suministrada en medios magnéticos (exógena) para tomar la decisión administrativa".

Es aquí como vemos claramente que la administración de impuestos pretende darle valor probatorio a la información exógena

\footnotetext{
${ }^{10}$ Sentencia 1323, de diciembre 9 de 1986.

${ }^{11}$ Sentencia 20130, Radicación: 66001-23-31-000-2012-00005-01 (20130), de agosto 6 de 2015.
} 
como prueba directa y con base en ella lograr que el contribuyente adicione ingresos en su liquidación privada.

En primera instancia, el tribunal declaró la nulidad parcial de los actos demandados, por cuando la administración incurrió en un error al apreciar la información exógena ingresando nuevamente valores que ya habían sido declarados.

Para el caso que nos ocupa, la sala concluye: "La información exógena es una herramienta que permite verificar los movimientos por parte del contribuyente, que se origina en los reportes de terceras personas de los que se puede apreciar la actividad comercial de un determinado sujeto. Si bien este tipo de cruces de información son un indicio suficiente para que la DIAN inicie una investigación, no son por sí solos una prueba que la Administración pueda considerar suficiente. Siendo el cruce de información un indicio de la existencia de un supuesto hecho irregular, debe probarse ese hecho mediante mecanismos y medios de prueba que lleven a la DIAN a la certeza de la existencia del hecho irregular".

\section{Valor probatorio de la información exógena en la jurisprudencia}

En este punto, se mencionarán varias sentencias, con hechos diferentes pero similar conclusión, en las cuales el Consejo de Estado concluye que la información exógena sí es prueba, desvirtuando las aportadas por el contribuyente, bien sea por su improcedencia o por su inutilidad.

Primera: "Considera la Sala que mal podía la Administración Local de Impuestos de Pereira, desestimar la información enviada por los terceros, (...) precisamente porque esta era la adecuada para esclarecer los valores de las cuentas por pagar, cuentas por cobrar, costos, impuestos descontables, gastos, deducciones; cuando era evidente la irregularidad en la contabilidad $(\ldots)^{12}$.

Segunda: un contribuyente presentó declaración de IVA correspondiente al primer bimestre del año 2000. La DIAN ordenó auto de inspección tributaria, posteriormente profirió requerimiento especial, donde propuso adicionar ingresos por operaciones gravadas, disminuir compras y servicios gravados y desconocer IVA descontable además de la sanción por inexactitud.

El actor se opuso al requerimiento especial argumentando una indebida valoración de las pruebas, pues los fundamentos de la DIAN se dan con base en la información exógena reportada por terceros. A esto, la administración de impuestos, mediante liquidación oficial de revisión, confirmó lo planteado en el requerimiento especial.

La DIAN manifestó "que le dio validez a la información exógena, porque la contabilidad no ofrecía confiabilidad al no llevarse en debida forma y por no contar con la totalidad de los comprobantes de orden interno que debían respaldarla, y que por ende no

${ }^{12}$ Sentencia 2005-00808, del 16 de marzo de 2011. 
reflejaba fielmente la realidad económica de la empresa"13.

El tribunal estimó "que no podía la DIAN dentro del proceso de fiscalización, desatender la información suministrada por terceros, cuando era evidente la inexactitud de la contabilidad de la contribuyente, que la hacía inepta tanto para demostrar la veracidad y exactitud de los valores reportados en la declaración de ventas del primer bimestre del año 2000, como para desvirtuar la información de los terceros".

El Consejo de Estado, por su parte, manifestó que, al no aportar la contabilidad por el contribuyente en debida forma y tampoco allegar otros soportes que cumpliesen los requisitos legales para su procedencia, se debía valorar la información exógena como prueba en contra del contribuyente.

Aquí se denota una posición diferente de la sala, pues a pesar de que el consejero ponente es prudente al no manifestar en ninguna parte de la sentencia si se le daba valor probatorio a la información exógena, induce todos sus argumentos a ello, y concluye que correspondía al contribuyente demostrar la existencia de los hechos y, al no poderlo hacer por la pertinencia en las pruebas aportadas, se le da credibilidad a la información exógena y se confirma la liquidación oficial.
Tercera: en esta sentencia, la sala le da valor probatorio a la información exógena y no es precisamente por la exactitud de la declaración ya presentada; por el contrario, es para determinar si existe o no la obligación de declarar, y toma como base la información exógena recaudada por la DIAN. La actora alega que no se encontraba obligada a presentar declaración de renta por el año gravable 2003, por cuanto la sociedad estaba inactiva desde el 6 de marzo del año 2003, y adjunta como prueba la resolución de cese de IVA de dicha fecha expedida por la misma DIAN y el certificado de cámara de comercio. La sala, al valorar dichas pruebas, concluye que no son útiles para demostrar la no obligatoriedad de cumplir con el deber de presentar declaración de renta y que, por el contrario, la información exógena recaudada prueba las transacciones, operaciones económicas y movimientos financieros realizados por la actora; por el contrario, la obliga a presentar declaración de renta por el año en discusión ${ }^{14}$.

En esta sentencia, la contribuyente presentó declaración de renta por el año gravable 1997. La DIAN profirió requerimiento especial, en el cual adicionaba ingresos y aplicaba sanción por inexactitud. Posteriormente, la confirmó mediante liquidación oficial de revisión y luego mediante resolución. El contribuyente contestó en debida forma cada uno de los actos administrativos.

\footnotetext{
${ }^{13}$ Sentencia 16502, Radicación número: 66001-23-31-000-2005-00805-01(16502), del 26 de noviembre de 2009.

${ }^{14}$ Sentencia 18829, Radicación número: 25000-23-27-000-2010-00080-01(18829), del 31 de julio de 2014.
} 
Manifestó la actora que la DIAN se fundamentó única y exclusivamente en la información exógena, que no verificó la existencia de dichos hechos con los contribuyentes informantes, y que desconoció la contabilidad aportada por él en sede administrativa.

La DIAN manifestó: "La información en medios magnéticos fue una prueba completa sobre la diferencia entre los ingresos declarados por la sociedad y los informados por quienes efectuaron los pagos. Que, además, dicha prueba nunca fue desvirtuada por la actora ni controvertida (...)"15.

El tribunal decidió que "No había lugar a la adición de ingresos porque la DIAN no valoró la contabilidad que allegó la contribuyente junto con los certificados del revisor fiscal, y liquidó oficialmente el impuesto con base en la información de terceros, que por ser prueba testimonial no contaba con la fuerza probatoria suficiente para desvirtuar la prueba contable aportada por la contribuyente. Consideró que la DIAN debió realizar visitas técnicas o procurar la exhibición de la contabilidad de esos terceros, para verificar la realidad de la información suminis- trada, pues lo reportado por esos terceros depende de una cuantía establecida para el respectivo periodo, y no incluye más de lo solicitado por la DIAN".

Para la sala la decisión del Tribunal se ajustó a Derecho, pues, en este caso, la simple información rendida por los terceros no era una prueba suficiente para adicionar los ingresos a la actora, y que la información exógena, al constituirse en prueba testimonial, tiene menor importancia que la prueba contable suministrada por el contribuyente investigado.

Al analizar las anteriores sentencias, se puede observar que no existe una sola posición, que no existe una sola línea jurisprudencial, que tanto la administración como el administrado tratan de tomar la información exógena a su conveniencia, rogando que se le dé o no valor probatorio, dependiendo de lo que se pretenda lograr y de la secuencia de los hechos. Como corolario de lo anterior, se puede concluir que existen claramente dos posiciones sobre el tema de estudio, las cuales se resumen en el siguiente diagrama:

\section{Diagrama 1}

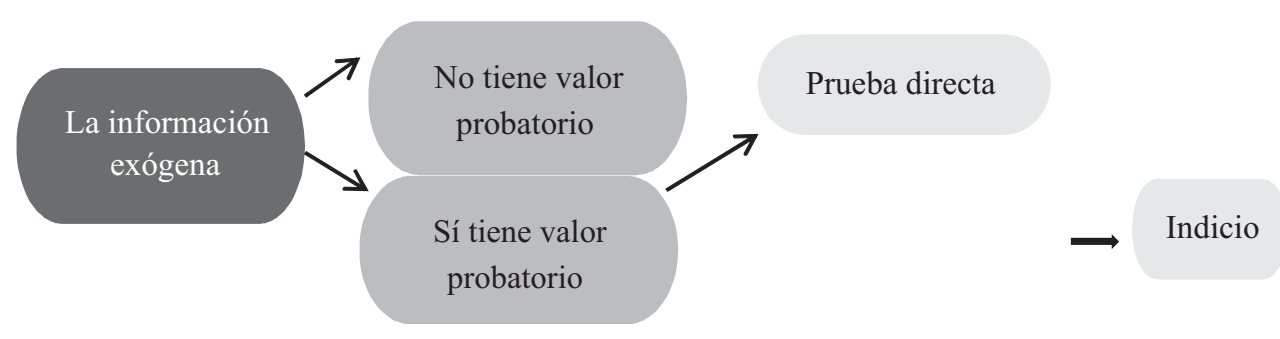

${ }^{15}$ Sentencia 16752, Radicación número: 25000-23-27-000-2002-01121-01(16752), del 10 de febrero de 2011 . 


\section{Valor probatorio de la información exógena otorgado por la Ley 1819 de 2016}

Cuando el desarrollo jurisprudencial es relativamente escaso frente al tema del valor probatorio de la información exógena; cuando los pronunciamientos existentes concluían basados en el Artículo 742 del Estatuto Tributario, que es simplemente un mecanismo de control; cuando la administración de impuestos pretendía en sus argumentos darle valor probatorio a la información en medios magnéticos; cuando no existía una norma de carácter legal que dijese lo contrario, nace un artículo introducido por la Ley 1819 de diciembre de 2016, en el cual se dice que la información exógena sí tiene valor probatorio. Lamentablemente, no lo dice de manera general para todos los procesos, lo dice única y exclusivamente para el tema de la liquidación provisional. Pero es muy interesante observar cómo el legislador, al ver la tecnicidad y el detalle de la información que le llega a la administración de impuestos vía exógena, le va dando suma importancia, la va elevando de categoría y le da valor probatorio.

El Artículo 255 de la Ley 1819 de junio 29 de 2016 adicionó el Artículo 764 al Estatuto Tributario y creó en el capítulo de procedimiento tributario la liquidación provisional, la cual es una figura nueva para declaraciones inexactas y omisos que cumplan con cierto tope de patrimonio o ingresos.

...Para tal efecto, la Administración Tributaria podrá utilizar como elemento probato- rio la información obtenida de conformidad con lo establecido en el artículo 631 y a partir de las presunciones y los medios de prueba contemplados en el Estatuto Tributario, y que permita la proyección de los factores a partir de los cuales se establezca una presunta inexactitud, impuestos, gravámenes, contribuciones, sobretasas, anticipos, retenciones y sanciones.

Así las cosas, es suficientemente claro que la administración de impuestos, sin necesidad de probar por otros medios que otorga el estatuto tributario la exactitud de los valores reportados en información exógena puede, amparada en la facultad que le otorga la ley y basada en la información que deben reportar los obligados en cumplimiento del Artículo 631 proferir la nueva figura de liquidación provisional. Esto es sumamente interesante y sirve como fundamento para el cometido en estudio, en la medida en que, aunado a la posición cambiante del Consejo de Estado, la ley ya estima un caso en el cual la información exógena por sí sola y de manera directa posee valor probatorio. Con ello, las demás situaciones de los procesos ordinarios del sistema tributario que también basan sus argumentos en los medios magnéticos pueden llegar a concluir como ya se ha hecho en un par de sentencias del Consejo de Estado que, en la medida en que las partes intervinientes en el proceso no logren probar por otros medios sus afirmaciones, deberá darse valor de verdad a la información obtenida de terceras personas, bien sea desde un enfoque directo o indirecto, como indicio grave tanto a favor o en contra del contribuyente que tenga como único fin hallar la realidad de los hechos económicos. 


\section{Conclusiones}

En términos generales, encontramos que a pesar de que la información exógena termina siendo un indicio, tanto la DIAN como la jurisdicción contencioso administrativa, dependiendo de los hechos, suelen darle valor de prueba.

Ahora bien, la información exógena es un mecanismo de control, pero también es una herramienta para que la administración de impuestos desarrolle sus argumentos, dándole valor probatorio a la información en medios magnéticos.

Es una prueba indirecta, como indicio. $\mathrm{Y}$ es tan así que hoy encontramos un artículo en la Ley 1819 de 2016, en el cual dice muy claramente que la información exógena sí tiene valor probatorio, de momento, exclusivamente para el tema de la liquidación provisional.

La información exógena constituye prueba testimonial y como tal está sujeta al principio de publicidad y contradicción. Al estar sujeta a estos principios deja de ser prueba directa para convertirse en indicio, en prueba indirecta de la existencia de un hecho económico fuente de obligación tributaria. Esto permite al administrado demostrar mediante otros mecanismos probatorios lo contrario a lo que la administración intuye.

Dependiendo de la forma como se desarrollan los hechos del proceso de discusión tributaria, dicha prueba testimonial en ciertos casos puede ser insumo directo de fallo en contra del contribuyente, pues el levantamiento de la presunción de veracidad de las declaraciones tributarias en armonía con la aplicación del juicio de valoración de las pruebas aportadas por el contribuyente convierten la información exógena en prueba contundente de inexactitud tributaria.

Cuando la relación entre el hecho indicador y el hecho indicado es tan estrecha que permite tener certeza de la vulneración de ley generada por el incumplimiento de obligaciones sustantivas o deberes formales, estamos frente a un indicio grave de evasión fiscal, y todo gracias a la utilidad de la información exógena.

De la existencia de múltiples fallos en cuanto al valor probatorio de la información en medios magnéticos se puede concluir que no existe una sola posición; no existe una línea jurisprudencial; que las decisiones de la sala son cada vez más cargadas de lógica, sana crítica y experiencia; que la dinámica de los hechos y el desarrollo de cada uno de los procesos de discusión genera diferentes conclusiones, y que es difícil sentar una sola postura frente al tipo de prueba que constituyen los medios magnéticos.

A pesar de lo anterior y de que en ocasiones se valora como prueba directa, en algunas otras como prueba indirecta, como indicio. Si hay algo claro, es que independientemente de la forma como se llame, sí conduce a lograr un mejor control de fiscalización, sí conduce a detectar omisos, inexactos... Sí tiene valor probatorio.

A pesar de que el Artículo 742 del Estatuto Tributario es muy claro al establecer que las decisiones de la administración se deben basar en hechos probados, en la práctica hay una evidente vulneración e inaplicabilidad de esta norma, por cuanto los funcionarios 
proyectan los actos administrativos teniendo claro que, una vez notificado, le corresponde al contribuyente demostrar lo contrario, y si no lo logra con pruebas documentales como la contabilidad y sus documentos soportes, la posibilidad de lograr un fallo a favor de la Dian es muy alta, pues la línea jurisprudencial está enfocada de tal manera.

La existencia de hechos económicos es el nacimiento de una cantidad de obligaciones para con el Estado en materia de impuestos. Estos hechos económicos son conocidos por el sujeto activo de la obligación gracias a la información exógena, convirtiéndose en insumo determinante para la lucha contra la evasión y elusión tributaria y reduciendo así un poco la brecha de la injusticia en esta materia. Aquel que contribuye en debida forma por convicción, por principios, por compromiso consigo mismo, con su familia y su país, actúa de manera justa con la Constitución y la ley, pero si lo comparamos con aquel que evade y elude sus obligaciones tributarias, se vuelve injusto, su tarifa efectiva de impuestos es mucho más alta. Es por eso que gracias a la información exógena y a las posibilidades de control que ella abre, lo injusto se vuelve cada vez más justo y, en últimas... "el conocimiento genera justicia".

\section{Referencias}

112 Resoluciones expedidas por el Director General de la DIAN desde el año 1997 al 19 de diciembre de 2017, en materia de solicitud de información exógena en materia tributaria.

Anders, Valentín (s.f.). Diccionario Etimológico. etimologias.dechile.net.

Arenas, Antonio Vicente (s.f.). Procedimiento penal. Quinta edición. Bogotá: Temis.
Arenas Salazar, Jorge (1988). Crítica del indicio en materia penal. Bogotá. Editorial Temis.

Carnelutti (s. f.). Sistema de derecho procesal civil.

Congreso de la República de Colombia (08 de julio de 2005) Ley Antitrámites. Ley 962 de 2005, Do 45963. Recuperado de: http://www.alcaldiabogota.gov.co/ sisjur/normas/Norma1.jsp?i=17004.

Congreso de la República de Colombia (29 de diciembre de 2016) Reforma Tributaria. Ley 1819 de 2016, DO 50101. Recuperado de: http://www.secretariasenado.gov.co/senado/basedoc/ley_1819_2016.html.

Congreso de la República de Colombia (30 de marzo 30 de 1989), Estatuto Tributario, Decreto 624 de 1989 , DO 38756. Recuperado de: http://www.alcaldiabogota. gov.co/sisjur/normas/Norma1.jsp?i=6533.

Consejo de Estado. Sala Plena de lo Contencioso Administrativo. Sección cuarta (10 de febrero de 2011). Sentencia CE 25000-23-27-000-2002-0112101(16752). C. P.:William Giraldo Giraldo.

Consejo de Estado. Sala Plena de lo Contencioso Administrativo. Sección cuarta. (16 de marzo de 2011). Sentencia CE 2005-00808. C. P.: Carmen Teresa Ortiz de Rodríguez.

Consejo de Estado. Sala Plena de lo Contencioso Administrativo. Sección cuarta (31 de julio de 2014). Sentencia CE 25000-23-27-000-2010-00080-01(18829). C. P.: Carmen Teresa Ortiz de Rodríguez.

Consejo de Estado. Sala Plena de lo Contencioso Administrativo. Sección cuarta. (06 de agosto de 2015) Sentencia CE 66001-23-31-000-2012-00005-01 (20130). C. P.: Jorge Octavio Ramírez Ramírez.

Consejo de Estado. Sala Plena de lo Contencioso Administrativo. Sección cuarta. (18 de febrero de 2016) Sentencia CE 25000-23-27-000-2011-0024901(20823). C. P.: Jorge Octavio Ramírez Ramírez.

Consejo de Estado. Sala Plena de lo Contencioso Administrativo. Sección cuarta. (26 de noviembre de 2009). Sentencia ce 66001-23-31-000-2005-0080501(16502). C. P.: Martha Teresa Briceño de Valencia.

Constitución Política de Colombia, 1991, [Const.] (1991) Articulo 95, numeral 9, Capítulo 5. Recuperado de: http://www.corteconstitucional.gov.co/inicio/ Constitucion \%20politica \%20de\%20Colombia.pdf.

Dellepiane, Antonio (1983). Nueva teoría de la prueba, Novena Edición, Bogotá. Temis. 
García Ramírez, Sergio (1974). Derecho Procesal penal.Primera edición, México, Editorial Porrúa S.A.

Hensel, A. (s. f.). Derecho Tributario.

Mittermaier, C. J. A. (s. f.). Tratado de la prueba en materia criminal.

Parra Quijano, Jairo (2011). Tratado de la prueba judicial-Indicios y presunciones. Colombia: Librería Ediciones del Profesional Ltda. Editorial ABC.

Piza, Julio Roberto (2015). La obligación tributaria y sus fundamentos constitucionales. Bogotá: Universidad Externado de Colombia.

Reyes Alvarado, Yesid (1984). La prueba indiciaria. Bogotá: Ediciones Librería del Profesional.
Rodríguez, Gustavo Humberto (s. f.). Procedimiento penal colombiano. Cuarta Edición. Bogotá: Ediciones Librería del Profesional.

Santofimio Gamboa, Jaime Orlando (2006). Tratado de Derecho Administrativo: Acto Administrativo, Tomo II, Bogotá D.C.: Universidad Externado de Colombia.

Whittingham García, Elizabeth (2006). Régimen probatorio colombiano. Revista No 137 Sep.-oct. 2006. Recuperado de: http://legal.legis.com.co/document?o bra $=$ rimpuestos $\&$ document $=$ rimpuestos $\_7680752 \mathrm{a} 7 \mathrm{e}$ 96404ce0430a010151404c.

Zornoza Pérez, Juan (2006). La prueba en Derecho tributario. Ponencia Instituto Colombiano de Derecho Tributario. Colombia. 